\title{
The impact of acute pain self-efficacy on pain intensity and the accurate recall of pain
}

\section{BACKGROUND}

Pain self-efficacy is one's belief in the ability to control and persist through pain. The purpose of this study was to examine the relationships between pain self-efficacy, immediate and delayed pain ratings, and accurate pain recall two weeks after an acute pain procedure.

\section{PARTICIPANTS AND PROCEDURE}

Two hundred three participants completed a tourniquet pain procedure. Pain self-efficacy was measured. An immediate pain rating was collected immediately following the procedure. A delayed pain rating was assessed in a two-week follow-up survey. Accurate pain recall was assessed by examining the difference between participants' immediate pain rating and their delayed pain rating.

\section{RESULTS}

Higher levels of pain self-efficacy were related to lower delayed pain rating two weeks later but not related to imme- diate pain ratings. Participants with higher pain self-efficacy were significantly more likely to underestimate their pain two weeks later than participants with lower pain self-efficacy, who tended to overestimate their previous pain.

\section{CONCLUSIONS}

This research highlights the important role of pain self-efficacy on the recall of pain. Those with higher pain self-efficacy were more likely to underestimate their pain two weeks later, while those with lower pain self-efficacy tended to overestimate their previous pain. Healthcare providers and caregivers should consider patients' pain self-efficacy in interpreting reports of pain, especially when these reports recall past pain.

\section{KEY WORDS}

self-efficacy; pain; pain recall; accuracy; pain catastrophizing; fear of pain

ORGANIZATION - 1: Massachusetts College of Pharmacy and Health Sciences (MCPHS) University, MA Boston, United

States · 2: Northeastern University, MA Boston, United States · 3: Bentley University, MA Waltham, United States AUthors' CONTRibutions - A: Study design - B: Data collection - C: Statistical analysis - D: Data interpretation .

E: Manuscript preparation · F: Literature search · G: Funds collection

Corresponding AUthor - Mollie A. Ruben, Ph.D., Massachusetts College of Pharmacy and Health Sciences (MCPHS) University, 179 Longwood Ave, MA Boston, United States, e-mail: mollie.ruben@mcphs.edu

to Cite this ARTICLE - Ruben, M. A., Jodoin, A. N., Hall, J. A., \& Blanch-Hartigan, D. (2018). The impact of acute pain self-efficacy on pain intensity and the accurate recall of pain. Health Psychology Report, 6(2), 136-145. doi: https:// doi.org/10.5114/hpr.2018.72068 


\section{BACKGROUND}

Physical pain is a major public health challenge (IOM, 2011a). Estimates suggest that more than one-third of American adults and one-fifth of European adults suffer from chronic pain (IOM, 2011a; Breivik, Collett, Ventafridda, Cohen, \& Gallacher, 2006). Nearly $80.00 \%$ of physician visits are due to pain symptoms (CDC, 2014). Because pain often goes untreated or undertreated (e.g., Deandrea, Montanari, Moja, \& Apolone, 2008), the American Pain Society (1995) encouraged clinicians to standardize pain assessment and treat pain as the fifth vital sign (Max et al., 1995). The fifth vital sign or self-report of pain is considered the gold standard of pain assessment and is part of providing patient-centered care by understanding patients' needs (IOM, 2011b).

Patients, however, are often asked to recall how much pain they experienced in the past or when participating in a specific activity. For example, older adults may have pain when doing daily chores such as making the bed, but not when undergoing a medical examination. Patients seeking physical therapy may experience pain while playing sports but not while they are performing controlled exercises in the physical therapy office.

Previous literature suggests that the memory or recall of pain can be biased, with a tendency to inflate the pain intensity, compared to momentary pain ratings (Broderick, Schwartz, Vikingstad, Pribbernow, Grossman, \& Stone, 2008). For example, in one experimental study, participants were randomly assigned to experience stress, through a verbal task in front of an audience giving negative nonverbal feedback, or not experience stress and then underwent a forehead cold pressor pain task (Gedney \& Logan, 2004). Pain ratings were assessed every 10 seconds by using a verbal rating scale from 0 , no pain, to 10 , worst pain imaginable. The level of pain recall was assessed by asking participants via a telephone interview 6 months after to recall their maximum experienced pain during the forehead cold pressor pain task. Across both conditions, participants recalled greater pain 6 months later than they actually experienced at the moment.

Accurate self-reports of past pain are important for clinical diagnosis, treatment decision-making, and appropriate medication prescribing. Patients overestimating their pain may receive unnecessary diagnostic tests or be prescribed unnecessary pain medication. Such overtreatment could have a spiraling effect, contributing to a dysfunctional self-concept in which patients think that they are weaker and less capable of handling pain than they actually are. Repeated pain overestimation by patients, even if unintentional, could lead providers to be suspicious about the truthfulness of patients' self-reports and weaken the therapeutic alliance (Nunnink \& Meana, 2007). Underestimation of past pain can also be prob- lematic; providers may miss diagnoses or may leave pain undertreated. By examining differences from momentary to delayed pain ratings we gain insight into what factors predict inaccuracy in pain recall.

In addition, many studies suggest that psychosocial factors contribute to the recall of pain. For example, in a study of healthy women undergoing a cold pressor task, women recalled higher levels of pain two weeks later than when they experienced the pain, and this was particularly pronounced among women who were high habitual symptom reporters (Walentynowicz, Bogaerts, Van Diest, Raes, \& Van den Bergh, 2015). In a similar study, children underwent a standard cold pressor task (Noel, Chambers, McGrath, Klein, \& Stewart, 2012), making a pain rating immediately after ending the task using the Faces Pain Scale-Revised (Hicks, von Baeyer, Spafford, van Korlaar, \& Goodenough, 2001). Two weeks after the laboratory session, children were contacted via phone interviews to assess their recall of pain. Those with higher levels of state anxiety recalled more pain two weeks later than those with lower levels of state anxiety.

One important psychosocial factor that has never been examined in the context of pain recall is pain self-efficacy. Pain self-efficacy is a person's belief in their ability to control, endure, and persist through pain and the negative emotions associated with pain (Miles, Pincus, Carnes, Taylor, \& Underwood, 2011). Although self-efficacy has been linked to momentary pain perception (O'Leary, 1985), the connection between self-efficacy and accurate pain recall has not been studied. A number of theoretical perspectives support the potential connection between pain self-efficacy and pain recall. General self-efficacy is the extent to which people believe they are capable of performing certain behaviors in order to accomplish specific goals (Bandura, 1994). Social cognitive theory suggests that the level and strength of general self-efficacy determines whether coping behavior will be exerted during aversive experiences and how long the effort will be sustained (Bandura, 1977). During an aversive experience, higher levels of self-efficacy predict more performance accomplishments and decreased emotional arousal (Bandura, 1982), as well as greater perseverance and resiliency in the face of obstacles such as physical illness or pain (Jackson, Iezzi, Gunderson, Nagasaka, \& Fritch, 2002). Grounded in social cognitive theory, pain self-efficacy develops across the lifespan from both previous pain experiences and the self-perception of pain.

In addition to social cognitive theory, fear-avoidance models take into account the cognitive and affective constructs involved in pain perception and experience (Vlaeyen, Kole-Snijders, Boeren, \& van Eek, 1995; McCracken, Zayfert, \& Gross, 1992; Asmundson, Norton, \& Vlaeyen, 2004). That is, the perception of pain does not act in a simple stimulus-response framework, but rather thoughts and feelings about
Impact of pain self-efficacy on pain recall 
Mollie A. Ruben, Adriana N. Jodoin, Judith A. Hall, Danielle Blanch-Hartigan pain can impact pain perception. These fear-avoidance models emphasize three main components that impact the way pain is felt and possibly even remembered. First, once pain is perceived, an individual's beliefs, such as their self-efficacy, determines whether the pain is interpreted as threatening or harmful. Second, a negative interpretation of pain, such as implied by having low pain self-efficacy, can induce physiological, cognitive, and behavioral fear responses. These fear responses fuel threat perceptions that continue a cycle of negative cognitions (e.g., "I am certain that I cannot get through this pain") and can lead to continued negative appraisal of pain and even disability (Asmundson, Norton, \& Vlaeyen, 2004) which may have implications for the recall of pain.

Consistent with the social cognitive theory and the fear-avoidance models, pain patients with higher levels of general self-efficacy report lower levels of pain intensity (Arnstein, Caudill, Mandle, Norris, \& Beasley, 1999), have more positive treatment outcomes (O’Leary, Shoor, Lorig, \& Holman, 1988), and exhibit more effective control of their pain (Lorig, Chastain, Ung, Shoor, \& Holman, 1989). Not only does pain self-efficacy impact the perception of chronic pain, but research on acute pain has shown that healthy participants undergoing a painful cold-pressor procedure report lower levels of pain intensity with higher levels of self-efficacy (Jackson et al., 2002). However, most published measures of self-efficacy beliefs, especially among acute pain samples, do not explicitly ask the participant or patient to take their pain into account; that is, they are not acute pain-specific self-efficacy measures (Lorig et al., 1989; Jensen, Turner, \& Romano, 1991). This is an important component of measuring confidence in one's ability to persevere not just in general, as general self-efficacy does, but in relation to persevering through and controlling pain.

Studying self-efficacy in the experience and recall of acute pain is important as most research on pain self-efficacy has focused on chronic pain (Arnstein et al., 1999; Anderson, Dowds, Pelletz, Edwards, \& Peeters-Asdourian, 1995; Denison, Asenlof, \& Lindberg, 2004). Additionally, the effect of pain self-efficacy on pain recall and accuracy in remembering past pain has not been studied and has clear implications for clinical practice. The current study examines the relationship between pain self-efficacy and ratings of acute pain both immediately following a pain experience and at two weeks' follow-up.

\section{CURRENT RESEARCH}

This study examined the association between pain self-efficacy and immediate and delayed pain ratings following an acute pain procedure. We hypothesized that 1) pain self-efficacy would be negatively asso- ciated with immediate pain ratings, 2) pain self-efficacy would be negatively associated with delayed pain ratings two weeks later, and 3) participants with higher levels of pain self-efficacy would recall their past pain more accurately than participants with lower levels of pain self-efficacy.

Along with the three main hypotheses, we examined the role of other cognitive and affective constructs, such as fear of pain (McNeil \& Rainwater, 1998) and pain catastrophizing (Sullivan, Bishop, \& Pivik, 1995), in accurate pain recall to rule out other possible mechanisms. Past research has shown that self-efficacy beliefs are more important in predicting short- and long-term outcomes such as disability among pain patients compared to pain catastrophizing (Denison, Asenlof, \& Lindberg, 2004), but these cognitive and affective constructs have not been compared in the context of accurate pain recall.

This study is novel to the field of pain and self-efficacy in several ways. First, this study is the first to our knowledge to incorporate a longitudinal design to examine the relationship between pain self-efficacy and accurate recall of pain after a passage of time. And second, this is the first study to examine the direction of bias, either over- or underestimation of past pain in relation to pain self-efficacy. Although we examine self-efficacy and pain in a non-clinical setting, the experimental nature of this study allows us to control many other factors that may interact with or impact the perception of pain and accurate recall of pain, which in turns allows for an understanding of the nature of pain self-efficacy and its impact on the pain experience and pain recall.

\section{PARTICIPANTS AND PROCEDURE}

\section{PARTICIPANTS}

Two hundred-three ( $36.00 \%$ male) undergraduate students from Northeastern University participated for partial course credit. Participants ranged in age from 18 to 22 . One hundred twenty-nine participants were Non-Hispanic White, 49 were Asian American, 12 were African American, 9 were Hispanic American, and 4 selected "other."

Participants were consented and the study protocol was approved by the Committee on Human Subject Protection of Northeastern University. All participants responded that they did not have the following health conditions that would preclude their participation in an acute pain procedure: high or low blood pressure, chronic migraine, asthma, heart disease, heart defect, circulatory problems, Reynaud's syndrome, diabetes, neurological disorders, numbness in hands and feet, cold/flu symptoms in the past 48 hours, or recent use of drugs/analgesics/antidepressants. Participants' resting blood pressure was taken to ensure it fell within an 
acceptable range for the procedure (100-140 systolic and below 90 diastolic). A manual inflation, automatic deflation blood pressure (BP) monitor with digital readout of systolic pressure, diastolic pressure, and pulse (Health Living model BM-501S; Samsung America) was used to assess participants' baseline blood pressure and pulse prior to the pain procedure.

\section{PROCEDURE}

Acute pain was induced through the tourniquet procedure. The tourniquet procedure is a validated and widely used procedure to induce acute pain in the laboratory (Ruben \& Hall, 2013; Smith, Egbert, Markowtiz, Mosteller, \& Beecher, 1966; Wilson \& Ruben, 2011). The tourniquet procedure involves wearing an inflated blood pressure cuff around the upper arm while performing handgrip exercises, which causes an increasing sensation of ischemic muscle pain by occluding blood flow to the arm and hand. A manual inflation, manual deflation aneroid sphygmomanometer (775 Series cuff; American Diagnostic Corporation) blood pressure cuff inflated to a constant pressure of $270 \mathrm{~mm} \mathrm{Hg}$ was used to occlude blood flow during the tourniquet procedure.

Before the procedure, participant hand grip strength was assessed using a Smedley spring hand dynamometer. The result of this hand grip strength test was used to distinguish which hand grip strength was used throughout the tourniquet procedure. One of three Harbinger Adjustable Hand Grips was used throughout the tourniquet procedure $(30,40$, or $50 \mathrm{lb}$ hand grip strength) determined as $50.00 \%$ of the participant's grip strength using the Smedley spring hand dynamometer.

Participants were instructed through the tourniquet procedure using an instructional video. In the instructional video, an actor playing the part of a physician instructed participants when to conduct the 20 hand grip exercises (every $7.5 \mathrm{~s}$ ). The instructions signaled when to "squeeze," "hold," and "release" the hand grip, and when to stop using the handgrip (after $2.5 \mathrm{~min}$ ). The female experimenter monitored the participant from the hallway, out of the participant's vision.

Participants were informed they could stop the pain procedure at any time by deflating the blood pressure cuff or alerting the experimenter who would deflate the blood pressure cuff for them. If the participant did not end the procedure, the experimenter ended the procedure after a maximum of 15 minutes by deflating the cuff.

After the tourniquet procedure, participants completed the post-pain questionnaire, which included the immediate pain rating, pain self-efficacy, fear of pain, pain catastrophizing and basic demographic questions. Two weeks after the pain procedure, participants were emailed a 5-minute survey, which asked them to recall their overall pain intensity during the tourniquet procedure and served as the delayed pain rating.

\section{MEASURES}

Immediate pain rating. Immediately after deflation of the cuff (i.e., when the pain experience ended) participants completed the post-pain questionnaire that asked them to rate their overall pain intensity during the procedure on a scale from 0 , no pain at all, to 100 , the most intense pain imaginable. This item served as the immediate pain rating.

Delayed pain rating. Two weeks after the pain procedure participants were sent a follow-up survey by email to assess delayed pain ratings. Participants were asked to rate their pain intensity during the procedure on a scale from 0 , no pain at all, to 100 , the most intense pain imaginable. There was a strong, positive correlation between the immediate pain rating and delayed pain rating, $r=.73, p<.001$. This strong, positive correlation shows that people were accurate in the relative sense. That is, those who felt more pain at the time of pain also reported more pain two weeks later relative to others who felt less pain at the time of pain and reported less pain two weeks later.

Pain self-efficacy. Pain self-efficacy was assessed using a modified General Self-Efficacy Scale (GSES) (Sherer, Maddux, Mercandante, Prentice-Dunn, Jacobs, \& Rogers, 1982). The original validated scale was created to assess a general sense of perceived self-efficacy with the aim to predict coping with daily hassles as well as adaptation after experiencing stressful life events. As was suggested by Schwarzer and Fuchs (1996), perceived self-efficacy should always be as situation-specific as possible, yet there is no known scale for perceived self-efficacy of acute pain. Therefore, the scale was adapted by the present investigators to pertain to pain by replacing "stressful life events" and "difficult problems" with "pain" and "physical discomfort." The GSES and other self-efficacy scales have been adapted in prior research to tap different types of health behaviors (Schwarzer \& Fuchs, 1996), and Bandura's (2006) guide for constructing self-efficacy scales was followed in modifying the items in the current study. The 16 items were rated on a 6-point rating scale from strongly disagree to strongly agree. An example item is "When I know something will cause physical discomfort, I am certain that I can get through it" (see Appendix for the full pain self-efficacy scale). The average of all items was used in the current study.

Fear of Pain Questionnaire (FPQ-III) (McNeil \& Rainwater, 1998). The FPQ-III is a validated 30-item measure of fear and anxiety associated with pain.
Impact of pain self-efficacy on pain recall 
Mollie A. Ruben, Adriana N. Jodoin, Judith A. Hall, Danielle Blanch-Hartigan
Participants are instructed to assess on a 5-point scale from "not at all" to "extremely" how much they fear the pain associated with a variety of situations that typically cause pain, e.g., "having someone slam a heavy door on your hand". The total score was used in the current study.

Pain Catastrophizing Scale (PCS) (Sullivan, Bishop, \& Pivik, 1995). The PCS is a validated 14-item measure that assesses the degree to which participants have specified thoughts and feelings when experiencing pain, e.g., "I worry all the time about whether the pain will end". Participants answer on a 5-point scale from "not at all" to "all the time". The total score was used in the current study.

\section{DATA ANALYSIS}

Linear regression models tested all three hypotheses, always adjusting for gender, as gender can play a large role in pain ratings, with women generally reporting more pain than men (Fillingim, King, Ribeiro-Dasilva, Rahim-Williams, \& Riley, 2009). An accurate recall of pain variable was created by subtracting the immediate pain rating from the delayed pain rating two weeks later. We did not take the absolute value of this variable because we were interested in the direction of inaccuracy, that is understanding whether those with lower levels of self-efficacy tended to under- or overestimate recall of pain, not just whether participants were accurate or inaccurate. More positive values on the accurate recall of pain variable show a tendency to overestimate pain two weeks later, while more negative values on the accurate recall of pain show a tendency to underestimate pain two weeks later. Values close to zero represent accurate recall of pain two weeks later.

Although we assessed the continuous relationship between pain self-efficacy and accurate recall of pain, this approach does not tell us whether higher pain self-efficacy predicts over- or underestimation of pain; therefore, we split pain self-efficacy into tertiles: low, moderate, and high pain self-efficacy. We examined with an analysis of variance (ANOVA) whether there were differences in the over- or underestimation of pain recall according to the levels of pain self-efficacy. Finally, we also analyzed the fear of pain and pain catastrophizing variables using the tertile split to rule out the possibility of other cognitive and affective constructs predicting accurate pain recall.

\section{RESULTS}

Of the 203 participants who took part in the pain procedure, 129 (64.00\%) completed the two-week follow-up survey that assessed participants' accurate recall of their pain.

\section{IMMEDIATE AND DELAYED PAIN RATINGS}

A paired samples- $t$ test on immediate and delayed pain ratings showed that on average, participants recalled significantly more pain two weeks later $(M=64.26, S D=20.89)$ than immediately after the pain task $(M=61.24, S D=20.61), t=2.27$, $p=.030$. There was also a significant positive correlation between immediate and delayed pain, $r=.73$, $p<.001$, such that participants who rated higher levels of pain immediately after the task also recalled higher levels of pain two weeks later.

\section{RELATIONSHIP BETWEEN PAIN SELF-EFFICACY AND PAIN RATINGS}

There was no difference in pain self-efficacy scores based on whether participants responded to the two-week follow-up, $t=1.57, p=.120, d=.23$ (responded $M=4.19, S D=0.74$; did not respond $M=4.36, S D=0.74)$. Because men $(M=4.38, S D=0.73)$ had marginally more pain self-efficacy compared to women $(M=4.18, S D=0.75), t=1.90, p=.060$, $d=.27$, we entered gender as a control variable into all regression analyses. The first hypothesis that pain self-efficacy would be negatively associated with immediate pain ratings was in the hypothesized direction but not significant (see Table 1 for regression results and Table 2 for correlations). The second hypothesis that pain self-efficacy would be negatively related to delayed pain ratings two weeks later was supported (Table 1).

\section{RELATIONSHIP BETWEEN PAIN SELF-EFFICACY AND ACCURATE PAIN RECALL}

To examine the third hypothesis, that higher levels of self-efficacy would predict inaccurately recalling pain, the correlation between the continuous self-efficacy variable and accurate pain recall was examined. Although pain self-efficacy was significantly negatively related to accurate pain recall (Table 2), it was unclear from the continuous accurate pain recall variable whether people low in self-efficacy were overestimating their pain and/or whether people high in self-efficacy were accurately recalling their pain or possibly even underestimating their pain. In order to address this issue, pain self-efficacy (low, moderate, and high levels) was entered into an ANOVA predicting accurate pain recall to examine whether the third hypothesis was supported. Results of the ANOVA supported the third hypothesis. There was a linear relationship between levels of pain self-efficacy and accurate recall of pain such that those with lower pain self-efficacy overestimated their pain while those with higher 
Table 1

Regression results of effect of pain self-efficacy on pain rating variables controlling for participant gender.

\begin{tabular}{|c|c|c|c|c|c|c|c|c|c|c|c|c|}
\hline \multirow[t]{2}{*}{ Variable } & \multicolumn{4}{|c|}{ Immediate pain rating } & \multicolumn{4}{|c|}{ Delayed pain rating } & \multicolumn{4}{|c|}{ Accurate pain recall } \\
\hline & $B$ & $S E B$ & $\beta$ & $\begin{array}{c}\text { Zero- } \\
\text { order } \\
\text { correlation }\end{array}$ & $B$ & $S E B$ & $\beta$ & $\begin{array}{c}\text { Zero- } \\
\text { order } \\
\text { correlation }\end{array}$ & $B$ & $S E B$ & $\beta$ & $\begin{array}{c}\text { Zero- } \\
\text { order } \\
\text { correlation }\end{array}$ \\
\hline $\begin{array}{l}\text { Pain } \\
\text { self- } \\
\text { efficacy }\end{array}$ & -2.76 & 1.95 & -.10 & -.11 & -7.53 & 2.38 & $-.27^{* *}$ & $-.28^{*}$ & -4.83 & 1.78 & $-.24^{* *}$ & -.24 \\
\hline Gender & 1.71 & 3.02 & .04 & .05 & 3.99 & 3.87 & .09 & .10 & 2.43 & 2.90 & .07 & .09 \\
\hline$R^{2}$ & & & .01 & & & & .08 & & & & .06 & \\
\hline$F$ & & & 1.29 & & & & $5.73^{* *}$ & & & & $4.16^{*}$ & \\
\hline
\end{tabular}

Note. ${ }^{*} p<.05 .{ }^{* *} p<.01 .{ }^{* * *} p<.001 . d f$ for immediate pain rating $=(2,201), d f$ for delayed pain rating and accurate pain recall $=$

$(2,127) . B$ is unstandardized coefficient and $\beta$ is standardized coefficient.

Table 2

Intercorrelations of pain self-efficacy and pain variables.

\begin{tabular}{|c|c|c|c|c|c|}
\hline & $M(S D)$ & 1 & 2 & 3 & 4 \\
\hline 1. Pain self-efficacy & $4.25(.75)$ & & & & \\
\hline 2. Immediate pain rating & $61.12(20.57)$ & -.11 & & & \\
\hline 3. Delayed pain rating & $64.26(20.89)$ & $-.29 * * *$ & $.73^{* * *}$ & & \\
\hline 4. Accurate pain recall & $3.02(15.16)$ & $-.24^{* *}$ & $-.35^{* * *}$ & $.38^{* * *}$ & \\
\hline $\begin{array}{l}\text { 5. Gender } \\
(\text { male }=0, \text { female }=1)\end{array}$ & $36 \%$ male & $-.13^{+}$ & .05 & .10 & .09 \\
\hline
\end{tabular}

Note. ${ }^{*} p<.05 .{ }^{* *} p<.01 .{ }^{* * *} p<.001 . N$ s range is $129-203$. Accurate pain recall calculated as the difference between the pain intensity rating made immediately after the pain and the recall of pain in the two-week follow-up survey.

pain self-efficacy recalled their pain more accurately with a tendency to underestimate their pain, $F(2,128)=4.49, p=.010, \mathrm{y}^{2}=.07$. The means, depicted in Figure 1, show that the low pain self-efficacy participants overestimated their pain on average $M=6.55$ points on the pain scale $(S D=12.83)$, the moderate pain self-efficacy participants overestimated their pain on average by $M=4.24$ points $(S D=18.57)$, while the high pain self-efficacy participants underestimated their pain on average by $M=3.03$ points $(S D=11.40)$. Tukey post hoc tests showed that the only significant difference was between those with low pain self-efficacy and high pain self-efficacy, $p=.050$, though the difference between moderate pain self-efficacy and high pain self-efficacy was marginal, $p=.070$.

To rule out the possibility of other fear-avoidance constructs predicting accurate pain recall, both pain catastrophizing and fear of pain were split into tertiles (low, moderate, and high) and analyzed in separate ANOVAs predicting accurate pain recall. Neither pain catastrophizing, $F(2,129)=.86, p=.420$, $\mathrm{\eta}_{\mathrm{p}}^{2}=.010$, nor fear of pain, $F(2,128)=.42, p=.660$, $\mathrm{n}_{\mathrm{p}}^{2}=.010$, significantly predicted accurate pain recall.

\section{DISCUSSION}

This is the first study to examine the lasting impact of pain self-efficacy on the recall of pain after an acute pain experience. This study adds to the current literature by extending the negative relationship between ratings of chronic pain and self-efficacy (Denison,

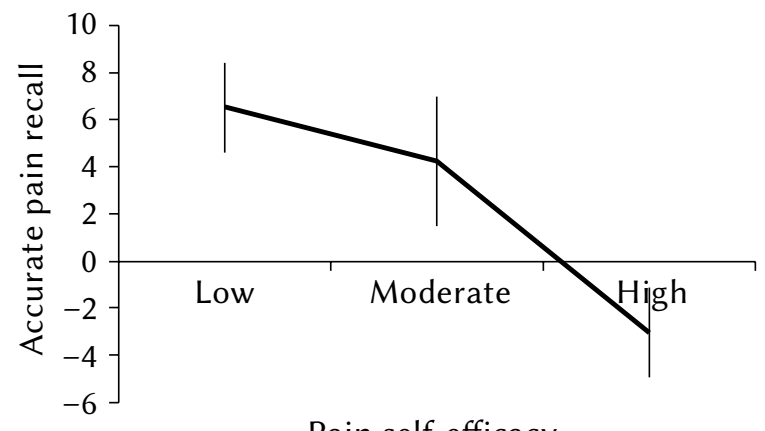

Pain self-efficacy

Note. Error bars are standard error. Accurate pain recall calculated as the difference between the pain intensity rating made immediately after the pain and the recall of pain in the two-week follow-up survey.

Figure 1. Accurate Pain Recall for three levels of pain self-efficacy.
Impact of pain self-efficacy on pain recall 
Mollie A. Ruben, Adriana N. Jodoin, Judith A. Hall, Danielle Blanch-Hartigan
Asenlof, \& Lindberg, 2004) to an acute pain paradigm. The results demonstrated that participants who had higher pain self-efficacy reported significantly less pain two weeks later. Additionally, participants with low levels of pain self-efficacy overestimated their pain at time 2 (relative to their immediate pain rating at time 1) compared to participants with high levels of pain self-efficacy, who underestimated their pain at time 2 (again, relative to their immediate pain rating at time 1). Although pain catastrophizing, one's disposition to ruminate, exaggerate, or have negative cognitive and emotional schema related to actual or anticipated pain experiences (Chaves \& Brown, 1987; Sullivan, Bishop, \& Pivik, 1995), has been linked in prior studies to higher levels of perceived pain intensity, higher clinical pain severity, more pain-related activity interference and higher rates of disability and depression (Edwards, Bingham, Bathon, \& Haythornthwaite, 2006; Sullivan et al., 2001), in the current research, pain catastrophizing did not predict accurate pain recall. In the context of fear-avoidance models, it appears that self-efficacy beliefs are more important contributors to the pain experience and pain recall compared to the other fear-avoidance constructs measured in this study - pain catastrophizing and fear of pain.

In the present study, low and moderate pain self-efficacy participants overestimated their pain two weeks later, while the high pain self-efficacy participants on average underestimated their pain. Past work has shown similar findings but has never examined underestimation of pain in the context of self-efficacy. The recall of pain by participants two weeks after this pain procedure parallels past research on memory for acute pain that found both retrospective over- and underestimation of pain. For example, in one study of dental patients who were asked to rate their pain at the time of a procedure and then 3 months later, those who were more anxious remembered their pain experience as more severe than it actually was, while those who were not as anxious recalled their pain more accurately (Kent, 1985). In terms of underestimation, Salovey, Smith, Turk, Jobe, and Willis (1993) explain that this is more likely to occur when the pain produces some type of positive outcome, e.g., childbirth. In one study examining pain during the childbirth experience, women's recalled pain ratings made 2 days postpartum were lower than their pain ratings made in three phases of labor (Norvell, Gaston-Johansson, \& Fridh, 1987). Similarly, Waldenstrom and Schytt (2009) examined women's positive perceptions of childbirth and how that impacted their perception of pain over time. Women who had a very positive or positive memory of the childbirth experience at 2 months after labor underestimated their pain at 1-year and 5-year follow-up. These positive memories of the childbirth experience could have been driven or at least explained by women's high self-efficacy for pain, but this has not been measured in past work.

This study examined self-efficacy in the case of induced, acute pain in a laboratory setting; therefore, the results may not generalize to clinical settings. The current study cannot establish the direction of the relationship between pain self-efficacy and pain ratings. There is a possibility that participants' experience of pain determined their pain self-efficacy ratings. However, the longitudinal nature of this study and the validated self-efficacy scale used suggest that this was not the case. Future research could manipulate pain self-efficacy to examine the causal relationship.

\section{IMPLICATIONS}

These findings on pain self-efficacy have important implications for healthcare settings. People with high pain self-efficacy have perceived control over their pain and may withstand painful stimuli and be more resilient during aversive experiences (Bandura, 1982). Self-efficacy is a psychological state that is changeable and therefore modifiable in the context of treatment (Lorig et al., 1989). For example, interventions that have used cognitive behavioral therapy to treat patients with rheumatoid arthritis enhanced patients' self-efficacy beliefs, which in turn reduced pain and joint inflammation, and improved psychosocial functioning (O'Leary et al., 1988). Through teaching effective coping skills via self-efficacy, clinicians can not only alter patients' experiences at the time of pain (by reducing pain intensity) but also increase their accurate recall of the painful experience in the future, which has implications for future health behaviors. For example, patients who experience less pain during a painful procedure may be more likely to follow up with their physicians or endure the painful procedure again. Accurately recalling pain intensity is beneficial in clinical settings to receiving appropriate treatments (Nunnink \& Meana, 2007). Additionally, pain self-efficacy should be measured as a potential mediator or moderator in clinical pain interventions. It is possible that some interventions that increase patients' cognitive preparation prior to a painful procedure may work through increasing patients' pain self-efficacy. Cognitive preparation has been shown to reduce preoperative and postoperative anxiety and pain (Mumford, Schlesinger, \& Glass, 1982). Future research should examine pain self-efficacy as the mechanism by which cognitive preparation and preparatory information impacts patients' anxiety and pain prior to, during, and after a painful procedure.

Based on the findings of this study, future research should attempt to improve pain self-efficacy for patients experiencing acute pain procedures. 
Researchers should investigate whether improving pain self-efficacy not only decreases self-reported pain and increases accurate pain recall, but whether it also translates into improved health outcomes such as treatment adherence, appointment keeping, and overall improvements in physical and mental health functioning.

\section{REFERENCES}

Anderson, K. O., Dowds, B. N., Pelletz, R. E., Edwards, W. T., \& Peeters-Asdourian, C. (1995). Development and initial validation of a scale to measure self-efficacy beliefs in patients with chronic pain. Pain, 63, 77-83.

Arnstein, P., Caudill, M., Mandle, C. L., Norris, A., \& Beasley, R. (1999). Self efficacy as a mediator of the relationship between pain intensity, disability and depression in chronic pain patients. Pain, 80 , 483-491.

Asmundson, G. J., Norton, P. J., \& Vlaeyen, J. W. (2004). Fear-avoidance models of chronic pain: an overview. In G. J. G. Asmundson, J. W. S. Vlaeyen, \& G. Crombez (Eds.), Understanding and Treating Fear of Pain (pp. 3-24). New York: Oxford University Press.

Bandura, A. (1977). Self-efficacy: toward a unifying theory of behavioral change. Psychological Review, 84, 191-215.

Bandura, A. (1982). Self-efficacy mechanism in human agency. American Psychologist, 37, 122-147.

Bandura, A. (1994). Self-efficacy. In V. S. Ramachaudran (Ed.), Encyclopedia of Human Behavior (Vol. 4, pp. 71-81). New York: Academic Press.

Bandura, A. (2006). Guide for constructing self-efficacy scales. Self-efficacy Beliefs of Adolescents, 5, 307-337.

Breivik, H., Collett, B., Ventafridda, V., Cohen, R., \& Gallacher, D. (2006). Survey of chronic pain in Europe: Prevalence, impact on daily life, and treatment. European Journal of Pain, 10, 287-287.

Broderick, J. E., Schwartz, J. E., Vikingstad, G., Pribbernow, M., Grossman, S., \& Stone, A. A. (2008). The accuracy of pain and fatigue items across different reporting periods. Pain, 139, 146-157.

Centers for Disease Control and Prevention. (2014). National hospital discharge survey: 2010. Atlanta (GA): CDC [online]. Retrieved from http://www.cdc.gov/ nchs/nhds.htm [accessed: February 21, 2017].

Chaves, J. F., \& Brown, J. M. (1987). Spontaneous cognitive strategies for the control of clinical pain and stress. Journal of Behavioral Medicine, 10, 263-276.

Deandrea, S., Montanari, M., Moja, L., \& Apolone, G. (2008). Prevalence of undertreatment in cancer pain. A review of published literature. Annals of Oncology, 19, 1985-1991.

Denison, E., Åsenlöf, P., \& Lindberg, P. (2004). Self-efficacy, fear avoidance, and pain intensity as pre- dictors of disability in subacute and chronic musculoskeletal pain patients in primary health care. Pain, 111, 245-252.

Edwards, R. R., Bingham, C. O., Bathon, J., \& Haythornthwaite, J. A. (2006). Catastrophizing and pain in arthritis, fibromyalgia, and other rheumatic diseases. Arthritis Care \& Research, 55, 325-332.

Fillingim, R. B., King, C. D., Ribeiro-Dasilva, M. C., Rahim-Williams, B., \& Riley, J. L. (2009). Sex, gender, and pain: a review of recent clinical and experimental findings. The Journal of Pain, 10, 447-485.

Gedney, J. J., \& Logan, H. (2004). Memory for stress-associated acute pain. The Journal of Pain, 5, 83-91.

Hicks, C. L., von Baeyer, C. L., Spafford, P. A., van Korlaar, I., \& Goodenough, B. (2001). The Faces Pain Scale-Revised: toward a common metric in pediatric pain measurement. Pain, 93, 173-183.

Institute of Medicine. (IOM). Committee on Advancing Pain Research, Care, and Education. (2011a). Relieving pain in America: A blueprint for transforming prevention, care, education, and research. Washington: National Academies Press.

Institute of Medicine. (IOM). (2011b). Crossing the Quality Chasm: A New Health System for the Twenty-first Century. Washington: National Academy Press.

Jackson, T., lezzi, T., Gunderson, J., Nagasaka, T., \& Fritch, A. (2002). Gender differences in pain perception: The mediating role of self-efficacy beliefs. Sex Roles, 47, 561-568.

Jensen, M. P., Turner, J. A., \& Romano, J. M. (1991). Self-efficacy and outcome expectancies: relationship to chronic pain coping strategies and adjustment. Pain, 44, 263-269.

Kent, G. (1985). Memory for dental pain. Pain, 21, 187-194.

Lorig, K., Chastain, R. L., Ung, E., Shoor, S., \& Holman, H. R. (1989). Development and evaluation of a scale to measure perceived self-efficacy in people with arthritis. Arthritis \& Rheumatism, 32, 37-44.

Max, M. B., Donovan, M., Miaskowski, C. A., Ward, S. E., Gordon, D., Bookbinder, M., ...Janjan, N. (1995). Quality improvement guidelines for the treatment of acute pain and cancer pain. Journal of the American Medical Association, 274, 1874-1880.

McCracken, L. M., Zayfert, C., \& Gross, R. T. (1992). The Pain Anxiety Symptoms Scale: development and validation of a scale to measure fear of pain. Pain, 50, 67-73.

McNeil, D. W., \& Rainwater, A. J. (1998). Development of the fear of pain questionnaire-III. Journal of Behavioral Medicine, 21, 389-410.

Miles, C. L., Pincus, T., Carnes, D., Taylor, S. J., \& Underwood, M. (2011). Measuring pain self-efficacy. The Clinical Journal of Pain, 27, 461-470.

Mumford, E., Schlesinger, H. J., \& Glass, G. V. (1982). The effect of psychological intervention on recov-
Impact of pain self-efficacy on pain recall 
Mollie A. Ruben, Adriana N. Jodoin, Judith A. Hall, Danielle Blanch-Hartigan ery from surgery and heart attacks: an analysis of the literature. American Journal of Public Health, 72, 141-151.

Noel, M., Chambers, C. T., McGrath, P. J., Klein, R. M., \& Stewart, S. H. (2012). The influence of children's pain memories on subsequent pain experience. Pain, 153, 1563-1572.

Norvell, K. T., Gaston-Johansson, F., \& Fridh, G. (1987). Remembrance of labor pain: how valid are retrospective pain measurements? Pain, 31, 77-86.

Nunnink, S., \& Meana, M. (2007). Remembering the pain: Accuracy of pain recall in endometriosis. Journal of Psychosomatic Obstetrics \& Gynecology, 28, 201-208.

O'Leary, A. (1985). Self-efficacy and health. Behaviour Research and Therapy, 23, 437-451.

O'Leary, A., Shoor, S., Lorig, K., \& Holman, H. R. (1988). A cognitive-behavioral treatment for rheumatoid arthritis. Health Psychology, 7, 527-544.

Ruben, M. A., \& Hall, J. A. (2013). "I Know Your Pain" Proximal and Distal Predictors of Pain Detection Accuracy. Personality and Social Psychology Bulletin, 39, 1346-1358.

Salovey, P., Smith, A. F., Turk, D. C., Jobe, J. B., \& Willis, G. B. (1993). The accuracy of memory for pain: not so bad most of the time. American Pain Society Journal, 2, 184-191.

Schwarzer, R., \& Fuchs, R. (1996). Self-efficacy and health behaviours. In M. Conner \& P. Norman (Eds.), Predicting health behaviour: Research and Practice with Social Cognition Models (pp. 163196). Buckingham: Open University Press.

Sherer, M., Maddux, J. E., Mercandante, B., PrenticeDunn, S., Jacobs, B., \& Rogers, R. W. (1982). The self-efficacy scale: Construction and validation. Psychological Reports, 51, 663-671.

Smith, G. M., Egbert, L. D., Markowitz, R. A., Mosteller, F., \& Beecher, H. K. (1966). An experimental pain method sensitive to morphine in man: The submaximtum effort tourniquet technique. Journal of Pharmacology and Experimental Therapeutics, 154, 324-332.

Sullivan, M. J., Bishop, S. R., \& Pivik, J. (1995). The pain catastrophizing scale: development and validation. Psychological Assessment, 7, 524-532.

Sullivan, M. J., Thorn, B., Haythornthwaite, J. A., Keefe, F., Martin, M., Bradley, L. A., \& Lefebvre, J. C. (2001). Theoretical perspectives on the relation between catastrophizing and pain. Clinical Journal of Pain, 17, 52-64.

Vlaeyen, J. W., Kole-Snijders, A. M., Boeren, R. G., \& Van Eek, H. (1995). Fear of movement/(re) injury in chronic low back pain and its relation to behavioral performance. Pain, 62, 363-372.

Waldenström, U., \& Schytt, E. (2009). A longitudinal study of women's memory of labour pain from 2 months to 5 years after the birth. BJOG: An In- ternational Journal of Obstetrics \& Gynaecology, 116, 577-583.

Walentynowicz, M., Bogaerts, K., Van Diest, I., Raes, F., \& Van den Bergh, O. (2015). Was it so bad? The role of retrospective memory in symptom reporting. Health Psychology, 34, 1166-1174.

Wilson, C. L., \& Ruben, M. A. (2011). A pain in her arm: Romantic attachment orientations and the tourniquet task. Personal Relationships, 18, 24-265. 


\section{Pain Self-Efficacy Scale}

1. When I know something will cause physical discomfort, I am certain that I can get through it.

2. One of my problems is that I cannot do something that will cause physical discomfort when I should. (rs)

3. If I can't do something that causes physical discomfort the first time, I keep trying until I can.

Impact of pain

4. I give up on painful tasks before completing them. (rs)

5. I avoid facing physical discomfort. (rs)

6. If something looks too physically difficult, I will not even bother to try it. (rs)

7. When I have something unpleasant to do, I stick to it until I finish it.

8. When I decide to go through with something uncomfortable, I do it right away.

9. When trying something that is physically demanding, I soon give up if I am not initially successful. (rs)

10. When I am in unexpected pain, I don't handle it well. (rs)

11. I avoid trying new things when they look too physically difficult for me. (rs)

12. Failure at a physical task just makes me try harder.

13. I feel insecure about my ability to do physically demanding things. (rs)

14. When in pain, I am a self-reliant person.

15. I give up easily when in pain. (rs)

16. I do not seem capable of dealing with physical discomfort when it comes up in life. (rs)

Note. Items with an (rs) were reverse scored. Ratings were made on a 6-point scale from strongly disagree to strongly agree. Higher scores reflect more pain self-efficacy. Modified from General Self-Efficacy Scale (GSES; Scherer et al., 1982) as recommended by Schwarzer and Fuchs (1996). 